\title{
Utilisation of two-stage waste incinerator bottom ash as a cement substitute in concrete
}

\author{
F. Kokalj \& N. Samec \\ University of Mariboru, Faculty of Mechanical Engineering, Slovenia
}

\begin{abstract}
Waste incineration still seems to be an essential technology in the concept of integrated waste management. However, the desirable quantity of waste incineration residue needs to be as low as possible. Therefore, related optimization of two-stage waste incineration technology has been performed with the main goal of producing lower amounts of boiler ash, fly ash and flue gas-treatment residue, all classified as hazardous waste. Most of the combustion residue should be incinerator bottom ash. Tests were performed on light fraction of municipal solid waste in a two-stage pilot scale waste incineration plant.

The goal of this investigation is to present utilisation possibilities of waste light fraction incineration bottom ash as a cement substitute in concrete. The produced incinerator bottom ash, formed in the primary chamber of the twostage incinerator, was analysed, tested and compared to other incinerator bottom ashes and cement. High resemblance of investigated bottom ash to cement was determined compared to other bottom ashes. Compressive and flexural strength and slump test were performed to characterise incinerator bottom ash and cement mixtures in concrete. It was found that after 28 days the flexural and compressive strengths of the binder linearly gradually decreases. The results show that it is possible to substitute $15 \mathrm{wt} \%$ of cement where low strength concrete is required.
\end{abstract}

Keywords: incinerator bottom ash, waste incineration, two-stage incinerator, concrete.

\section{Introduction}

Municipal waste - although classified as non-hazardous - still causes air, water and soil pollution during its decay when deposited in landfills without proper 
pre-treatment. Hence, today's modern landfills for municipal solid waste (MSW), built to prevent almost all pollution, have a complex design. This makes the dumping space for a volume unit of waste rather expensive even if a locally acceptable dumping site can be found in the first place.

The Slovenian population, just as in the rest of the European Union, produces approximately $500 \mathrm{~kg}$ of MSW per person each year. In order to meet modern standards for waste management, Slovenian society has accepted European philosophy and legislation in the field of waste management. Waste reduction, re-use and recycling are already successful in waste stream minimisation. In addition the composting of separately collected bio-degradable fraction has recently been under way. The remaining fraction of the waste stream still goes directly to landfills. National and local waste legislation sets high standards and there are some plans to build regional waste management centres involving smaller two-stage waste incinerators (TSWIs) especially for the energy utilisation of a higher calorific value waste fraction called light fraction.

TSWI was originally designed for industrial, medical and hazardous waste incineration since, in the past, legislation had set higher standards for the thermal treatment of hazardous waste compared to MSW. These incinerators had small capacity and were mostly batch fired. The main intention when installing a second combustion chamber was to improve the destruction of organic compounds.

In TSWI light fraction is reduced by about $90 \%$ of mass during combustion, leaving only $10 \%$ of incineration residues representing mostly IBA and minor amounts of fly ash, boiler ash and flue gas-treatment residue classified as hazardous waste. The IBA's composition and its amount of TSWI fed by light fraction differ drastically from the IBA of mass burn grate waste incinerators (MBGIs) fed by non separated MSW. It offers some additional possibilities for IBA utilisation from TSWI.

It is important to distinguish between the treatment of IBA for utilisation, and for disposal. When treatment occurs for the purpose of disposal, it is economically advantageous to limit the use and cost of the process treatment, e.g. additives, while maintaining compliance with the regulations. In the case of IBA utilisation, the processes' economics, including the composition of the final product, become very different, especially when the IBA component represents only a fraction of the final product [1]. The regulatory and economic circumstances relating to natural resources and civil engineering practices, prevailing in various countries, can reflect the attitude adopted towards the utilisation of IBA. The range of applications for which IBA from MBGI is used commercially usually includes: landfill cover (daily or final), road foundations, wind and sound barriers, lightweight concrete aggregate, structural fill, aggregate in asphalt, shore-line protection and marine reefs.

The utilisation of different kinds of ash from coal and MSW combustion for concrete production was recently reported in literature $[2,3,4,5,6]$. Because of typical composition $\left(40-60 \mathrm{wt} \%\right.$ of $\mathrm{SiO}_{2}$ and $2-20 \mathrm{wt} \%$ of $\left.\mathrm{CaO}\right)$, which is far from cement composition, most of the ash investigated in these studies has been used as filler substituting for a part of the natural aggregate. IBA from TSWI 
containing about $24 \mathrm{wt} \%$ of $\mathrm{SiO}_{2}$ and about $40 \mathrm{wt} \%$ of $\mathrm{CaO}$ has quite similar composition to cement usually containing $17-24 \mathrm{wt} \%$ of $\mathrm{SiO}_{2}$ and $55-65 \mathrm{wt} \%$ of $\mathrm{CaO}$. It can be considered, with such composition as a good substitute for cement in concrete. Cement is a hydraulic binder and the fundamental ingredient of concrete. In general, it represents about $15 \%$ of a concrete's volume and around $45 \%$ of its cost. Concrete is one of the major materials in the construction industry and about 4.5 billion metric tons of concrete are cast each year worldwide [7]. In Slovenia this value is up to $1.5 \cdot 10^{6}$ tons $\left(6 \cdot 10^{5} \mathrm{~m}^{3}\right)$ [8]. Approximately $90 \%$ of this quantity is concrete with a characteristic compressive strength of $40 \mathrm{MPa}$ or less.

The aim of the presented work has been the investigation of some significant concrete properties produced by the utilisation of IBA from the pilot scale TSWI. However, by incorporating waste materials into permanent compounds, their interaction with the environment is diminished and, at the same time, the required landfill space is radically reduced.

\section{Description of pilot scale TSWI}

Two-stage incineration technology shares the common idea of two divided chambers. The primary goal was to create even better and environmentally friendlier devices that will produce lower toxic emissions of particles and gases. This technology is today technically feasible and economically comparable with mass burn incinerators in MSW treatment. Figure 1 schematically shows the pilot scale TSWI used in this research work.

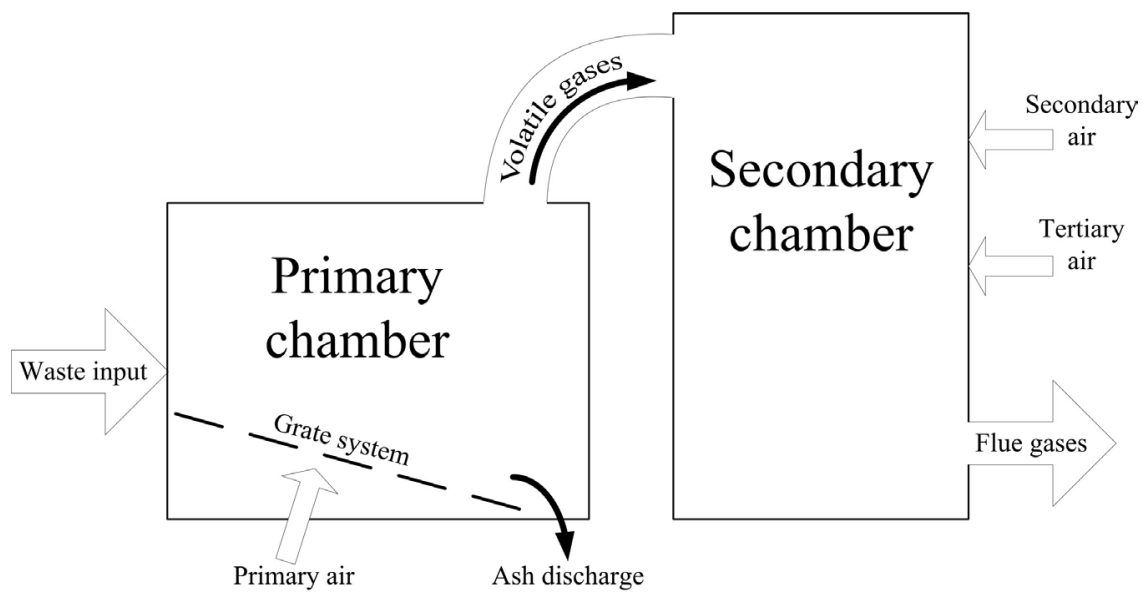

Figure 1: Schematic presentation of pilot scale TSWI.

In general TSWI should provide better combustion leading to a lower release of volatile organic compounds and carbon monoxide. In addition, the low air flow in the primary chamber results in lower entrainment of particulate matter in 
the flue gases, which in turn reduces other particulate-borne pollutants such as heavy metals, dioxins and furans. In practice the two-stage combustion incinerator relies on semi-pyrolysis, based on sub-stoichiometric combustion of the waste in the primary chamber, and excess air in the secondary chamber, together assuring good combustion conditions, low emissions and lower consumption of added fuel, if necessary. The waste is combusted by the insufficiency of air providing incomplete combustion and, therefore, there are a high proportion of incomplete combustion products, which pass through to the second stage, where they finally burn out. In the primary chamber warming, drying and semi-pyrolitic gasification of the waste at temperatures from 800 to $1050 \mathrm{~K}$ take place, and in the secondary combustion chamber mixing of the volatile gases with air, ignition and complete combustion at temperatures up to $1550 \mathrm{~K}$ occurs. Relatively low entrainment of particulate matter in the first stage and a complete combustion condition in the second stage result in less - polluted raw gases. Consequently, the flue gas-treatment devices are less demanding, cheaper and produce less residues than standard MBGI. The quantities of total dust and some toxic pollutants in raw gas for different types of incinerators are given in Table 1 as an example. It can be seen that MBGI's produce many more pollutants than optimized TSWI. In the worst case scenario MBGI's produce more than two orders of magnitude more pollutants than TSWI, also causing higher amounts and more contaminated flue gas-treatment residuals.

Table 1: Emission's comparison of untreated flue gases from standard MBGI and optimised TSWI

\begin{tabular}{|l|c|c|c|c|}
\hline $\begin{array}{l}\text { Parameter/ } \\
\text { Substance }\end{array}$ & WI Directive [15] & TSWI & MBGI [16] & MBGI [17] \\
\hline Total dust & 10 & 44 & $\begin{array}{c}2000- \\
15000\end{array}$ & $2000-6000$ \\
\hline $\mathrm{CO}$ & 50 & 7.5 & $50-600$ & $20-500$ \\
\hline $\mathrm{TOC}$ & 10 & 1.6 & & \\
\hline $\mathrm{SO}_{2}$ & 50 & 10 & $200-800$ & $300-600$ \\
\hline $\mathrm{NO}_{\mathrm{x}}$ & 200 & 60 & $200-400$ & $200-600$ \\
\hline $\mathrm{HCl}$ & 10 & 18 & $400-1500$ & $500-1200$ \\
\hline $\mathrm{HF}$ & 1 & 0.28 & $2-20$ & $1-10$ \\
\hline PCDD/F & 0.1 & 0.0025 & - & $1-10$ \\
\hline $\begin{array}{l}\text { NOTE: All concentrations are expressed in }\left(\mathrm{mg} / \mathrm{Nm}^{3}\right), \text { except PCDD/F which } \\
\text { are expressed in }(\mathrm{ng} \text { TE/m }\end{array}$ ) \\
\hline
\end{tabular}

It should be noted that the results for TSWI were achieved after a special optimisation process of the major operating conditions (i.e. amounts of air, temperatures, residence time, grate moving frequency, etc.). TSWI optimisation was divided into two parts. Firstly, the optimisation of combustion conditions in the primary chamber to produce the desired quality of bottom ash, and secondly the optimisation of conditions in the secondary chamber to achieve complete combustion of the volatile gases coming from the primary chamber. 
In the primary chamber optimisation was the incineration residuals' oriented optimisation of the process parameters. The basic idea of substoichiometric conditions, relatively low temperatures and legislative demand for ash quality was retained at all times. The waste input stream for the presented investigation was the light fraction of MSW as mentioned previously in introduction. It is a waste fraction with a relatively high heating value of about $18 \mathrm{MJ} / \mathrm{kg}$ and mostly involves paper, chard board, wood, different sorts of plastics and textiles, representing approximately $50 \%$ of total MSW stream. Optimisation peak was achieved with the lowest possible temperature of $850 \mathrm{~K}$ and only $70 \%$ of the theoretically needed air for complete combustion in the primary chamber. Low temperatures and small amounts of oxygen did not allow most of the toxic heavy metals to leave the primary chamber and they remained in the bottom ash.

The composition of the IBA and the presence of toxic metals are directly dependent on the input waste's composition and also the incinerator's operating conditions. These factors have a direct influence on the IBA's quality and composition, also determining its utilisation possibilities. However, from a technical stand point more work could be done on operating condition optimisation, and incineration technology. The waste composition on the other hand depends strongly on legislative demands and population habits.

The second part for the optimisation of pilot scale TSWI operation was conducted with the help of a CFD programme package named CFX. The operating conditions and secondary and tertiary air flows of second combustion chamber were investigated and optimised, in order to achieve complete combustion conditions. The so-called 3T parameters (temperature, turbulence/mixing and residence time) were examined and optimised to achieve homogenous temperature filed (minimise regions of lower temperatures), increased mixing efficiency of air and volatile gases, and ensure proper residence time. Corrections were made to the design and operating conditions of secondary combustion chamber based on broad computer analyses. The results of a complete numerical combustion modelling optimisation of the secondary combustion chamber were tested on the existing waste incinerator and produced the expected good results. The raw gas emissions of this optimised combustion chamber are presented in Table 1. The emission results for the carbon monoxide prove that combustion is practically complete. More detailed results and discussion can be found in the literature [9].

\section{Experimental set up}

The study was performed with IBA from pilot scale TSWI only, operating under optimised conditions for the primary and secondary chambers. The binding abilities of the IBA from the primary chamber were investigated and an acceptable level of IBA in the total binder was determined and consistency, density and strength were studied.

The IBA's binding abilities were tested according to the standard EN 196-1 [10]. Specimen mixtures were prepared with $450 \mathrm{~g}$ of binder and $225 \mathrm{~g}$ of water, giving a water/binder (W/B) ratio of 0.5 . The aggregate mass of $1350 \mathrm{~g}$ was 
quartz sand with grain sizes from 0 to $2 \mathrm{~mm}$ in accordance to EN 196-1 standard requirements. Pure cement designated as CEM I 42.5 R was used as binder for the preparation of a reference mixture. The standard EN 197-1 [11] prescribes Portland cement with a designation CEM I $42.5 \mathrm{R}$ with at least $95 \mathrm{wt} \%$ of clinker minerals, having a compressive strength of at least $42.5 \mathrm{MPa}$ after 28 days but not exceeding $62.5 \mathrm{MPa}$. R stands for the rapid development in strength during the early stage of hydration. Subsequent specimen mixtures were made with a binder which consisted of cement and IBA. The weight per cent of IBA in the total binder varied from 5 to $40 \mathrm{wt} \%$. Originally the IBA taken from TSWI was in the form of flakes with sizes from 1 to $20 \mathrm{~mm}$. It was ground using a ball mill and sieved through a $90 \mu \mathrm{m}$ screen in order to obtain a suitable granular composition. The sizes and shapes of the IBA particles depend on the incineration process, as previously discussed. Literature [5] reported that the particles of IBA were rather globular in shape with sizes from 4 to $20 \mathrm{~mm}$ and other work [12] reported more than $37 \%$ of IBA was over $4.76 \mathrm{~mm}$. The composition of IBA and CEM I $42.5 \mathrm{R}$ was determined by X-ray diffraction (Table 2). Table 2 also presents the composition of some other IBA-s from different MBGI's. The presented results show that TSWI IBA is superior in terms of composition resemblance to cement when compared to other results from literature $[6,13]$.

Table 2: Chemical composition of cement CEM I $42.5 \mathrm{R}$ and IBA from TSWI and other MBGI's

\begin{tabular}{|l|c|c|c|c|}
\hline \multirow{2}{*}{ Oxide } & \multicolumn{5}{|c|}{ Content (wt. \%) } \\
\cline { 2 - 5 } & CEM I 42.5 R & IBA (TSWI) & MBGI IBA [6] & MBGI IBA[13] \\
\hline $\mathrm{SiO}_{2}$ & 22.3 & 24 & $41.13-56.99$ & 41.2 \\
\hline $\mathrm{Al}_{2} \mathrm{O}_{3}$ & 5.83 & 14.8 & $9.2-11.35$ & 12.7 \\
\hline $\mathrm{Fe}_{2} \mathrm{O}_{3}$ & 2.17 & 2.7 & $3.97-8.61$ & 7.6 \\
\hline $\mathrm{CaO}$ & 60.81 & 39 & $13.22-19.77$ & 16.1 \\
\hline $\mathrm{MgO}$ & 2.82 & 1.7 & $3.46-3.85$ & 1.9 \\
\hline $\mathrm{Na}_{2} \mathrm{O}$ & 0.34 & 0.9 & $2.84-5.87$ & 2.8 \\
\hline $\mathrm{K}_{2} \mathrm{O}$ & 0.72 & 0.2 & $1.35-1.57$ & 1.0 \\
\hline $\mathrm{SO}_{3}$ & 2.75 & - & - & - \\
\hline
\end{tabular}

Nine specimens of size of $40 \mathrm{~mm}$ x $40 \mathrm{~mm}$ x $160 \mathrm{~mm}$ were cast from each mixture. They were kept in a mould for 24 hours. They were then stored in a $100 \%$ moist environment at $22 \pm 2{ }^{\circ} \mathrm{C}$. Specimens were tested for flexural and compressive strength after 2,7 and 28 days respectively.

The bulk density of the gravel with a granular composition was $1906 \mathrm{~kg} / \mathrm{m}^{3}$. The referenced concrete mixture was designed to reach a compressive strength of $40 \mathrm{MPa}$. Fresh concrete was tested for its workability. Namely, the quality of casting and compacting depends on it and, thereby, workability has a significant impact on the strength and durability of the concrete. There is no widespread standard test available for workability, which is best defined as the amount of useful internal work necessary to produce full compaction [14]. Thus, the slump 
of a concrete cone is often measured and the term consistency is used to describe this property. After executing the standard slump test for the purpose of this experiment, six cubical specimens with edge lengths of $100 \mathrm{~mm}$ were cast from each mixture. Specimens were taken out of the mould after 24 hours and kept in a $100 \%$ moist environment at $22 \pm 2{ }^{\circ} \mathrm{C}$. Compressive strength was determined after 7 and 28 days.

\section{Results and discussion}

The dependence of flexural and compressive strengths on the content of IBA is given in Figures 2 and 3. A linear decrease in both flexural $f_{f}$ (Figure 2) and compressive $f_{c}$ (Figure 3 ) strengths was observed. Hence, the following relationships were applied:

$$
\begin{aligned}
& f_{f}=f_{f 0}-k_{f} C \\
& f_{c}=f_{c 0}-k_{c} C
\end{aligned}
$$

where $C$ is the wt $\%$ of IBA in the binder, $f_{f 0}$ and $f_{c 0}$ denote the strength of the reference mix (without IBA), whereas the slope of the straight line denoted by $k_{f}$ and $k_{c}$ represents the reduction rate of strength. Values of all parameters after 2, 7 and 28 days are summarised in Table 3. Since the hydration of cementitious materials is a time - dependent process which can last up to several years, it was expected that the values of $f_{f}$ and $f_{c}$ would increase with elapsed time. Also, it is interesting to observe that the values of $k_{f}$ and $k_{c}$ decreased with time. This leads to the conclusion that IBA develops strength in the later stage of hydration compared to CEM I 42.5 R. A possible reason for this observed behaviour is that the temperature in the primary chamber is too low for the formation of alite $\left(3 \mathrm{CaO} \cdot \mathrm{SiO}_{2}\right)$. It is an essential compound for the strength of concrete in the early stage of the hydration process. Furthermore, the quantity of $\mathrm{CaO}$ is insufficient compared to cement, for the formation of all cementitious compounds.

Table 3: $\quad$ Parameters defining the bottom ash (IBA) $\mathrm{wt} \%$ in the binder having an influence on flexural and compressive strength. $f_{f 0}$ and $f_{c 0}$ denote flexural and compressive strength at $0 \mathrm{wt} \%$ of IBA. Curve slopes in fig 2 and 3 (eqn (1) and (2)) are denoted by $k_{f}$ and $k_{c}$.

\begin{tabular}{|l|l|l|l|l|}
\hline \multirow{2}{*}{$\begin{array}{l}\text { Time } \\
(\text { days })\end{array}$} & \multicolumn{3}{|l|}{ Flexural } & \multicolumn{2}{l|}{ Compressive } \\
\cline { 2 - 5 } & $f_{f 0}(\mathrm{MPa})$ & $k_{f}(\mathrm{MPa} / \% \mathrm{IBA})$ & $f_{c 0}(\mathrm{MPa})$ & $k_{c}(\mathrm{MPa} / \% \mathrm{IBA})$ \\
\hline 2 & 4.03 & 0.054 & 28.48 & 0.352 \\
\hline 7 & 6.57 & 0.051 & 38.96 & 0.269 \\
\hline 28 & 8.13 & 0.028 & 52.14 & 0.230 \\
\hline
\end{tabular}




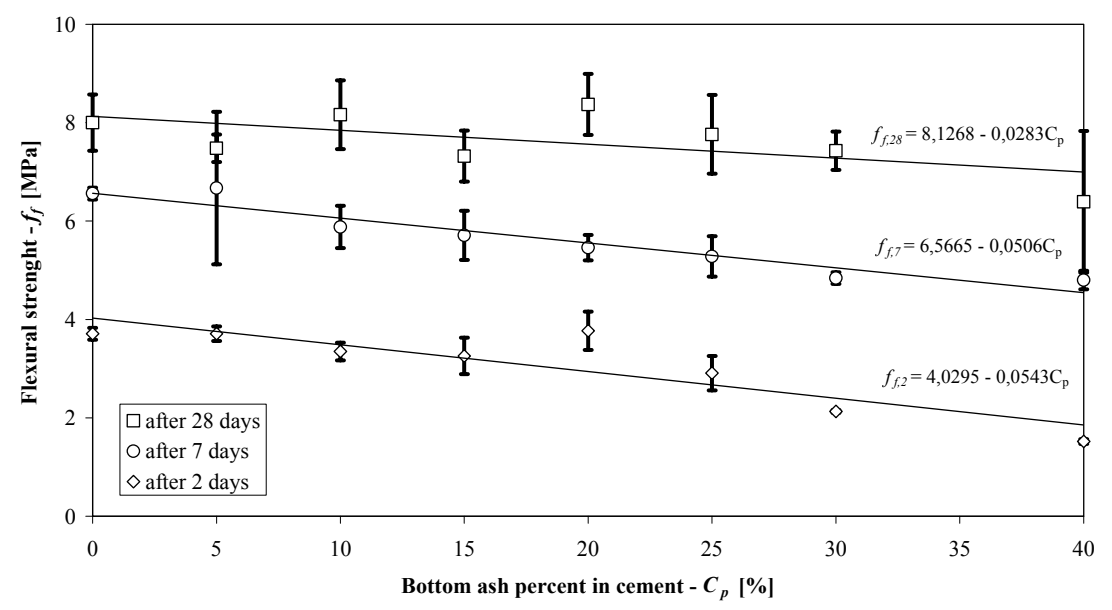

Figure 2: Flexural strengths of cement after 2, 7 and 28 days regarding incinerator bottom ash portion

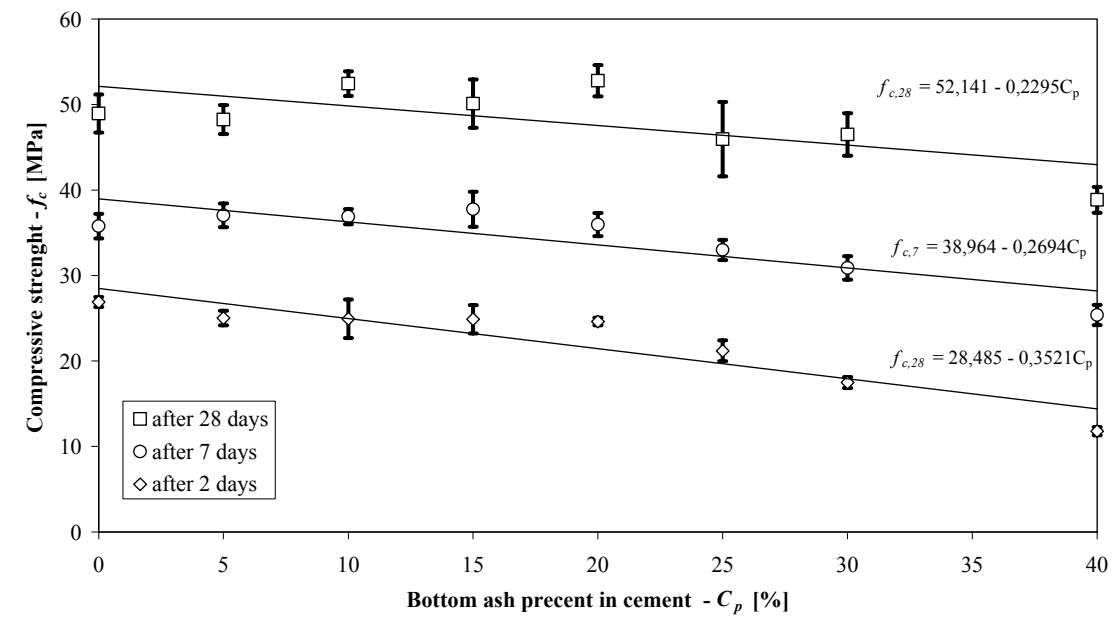

Figure 3: Compressive strengths of cement after 2, 7 and 28 days regarding incinerator bottom ash portion

Standard EN 197-1 [11] sets two acceptance conditions for the compressive strength of cement CEM I 42.5 R:

- $\quad$ after 2 days it should be at least $20 \mathrm{MPa}$,

- $\quad$ after 28 days it should reach at least $42.5 \mathrm{MPa}$ but should not exceed $62.5 \mathrm{MPa}$.

Results show that the early strengths are affected more when increasing the $w t \%$ of IBA in the binder. Thus the first above condition is more essential. Hence, the maximum content of IBA in the total binder calculated by eqn. (2), 
which still satisfies the second condition, is about $25 \mathrm{wt} \%$. Taking into account a safety factor of 0.7 , the acceptable level of IBA in the binder was established as $15 \mathrm{wt} \%$ and was further applied for the study of concrete.

The consistency was investigated using the slump test. The concrete with no IBA had a slump of $105 \mathrm{~mm}$ and the one with $15 \mathrm{wt} \%$ IBA had a slump of $55 \mathrm{~mm}$. Interestingly the slump is significantly reduced when the binder contains $15 \mathrm{wt} \%$ of IBA. In general, lower slump should result in poorer workability, so one would expect lower density for such concrete mixtures. The results for the concrete mixtures' densities again display an interesting fact. The concrete density of cement is only $2310.7 \mathrm{~kg} / \mathrm{m}^{3}$ and $2324.8 \mathrm{~kg} / \mathrm{m}^{3}$ with $15 \mathrm{wt} \%$ of IBA. When the binder contains cement as well as IBA, the density of the concrete is unaltered although the slump is reduced.

The compressive strengths of concrete mixtures after 7 days are $31.6 \mathrm{MPa}$ with no IBA content and $34.7 \mathrm{MPa}$ with $15 \mathrm{wt} \%$ of IBA. After 28 days the compressive strength raises to $40.6 \mathrm{MPa}(0 \mathrm{wt} \%$ IBA) and $43.4 \mathrm{MPa}(15 \mathrm{wt} \%$ IBA). Although it was established that when IBA represents $15 \mathrm{wt} \%$ of the binder, flexural strength is reduced by approximately $10 \%$, this was not generally observed in concrete specimens when the compressive strength was investigated. The compressive strengths of the mixtures with pure gravel aggregate even increased when IBA was used - surprisingly even after 7 days.

\section{Conclusion}

IBA composition and the presence of some hazardous components depend strongly on input waste composition and incinerator operating conditions. Furthermore, incineration technology (i.e. MBGI, TSWI, fluidised bed incinerator, etc.) can additionally influence IBA quality and composition, also determining its utilisation possibilities.

It was found that IBA, formed in the primary chamber of TSWI when it has been fed by light MSW fraction, involves the same significant components (i.e. $\mathrm{SiO}_{2}$ and $\mathrm{CaO}$ ) and comparable amounts as cement. Therefore, the feasibility of its application in concrete as a cement supplement was investigated and it was found that after 28 days the flexural and compressive strength of the binder's linearly gradually decreases. The presented results show that it is reasonable to use a binder containing IBA where a lower strength of concrete elements is required

Supposing that all MSW light fraction in Slovenia is incinerated with similar TSWI technology to that used in the experiment, then around $5 \cdot 10^{4}$ tons of IBA would be produced per year. About $4 \cdot 10^{4}$ tons of IBA or $80 \%$ of IBA could be re-used for the production of concrete with a characteristic compressive strength of $40 \mathrm{MPa}$ or less by supplementing $15 \mathrm{wt} \%$ of cement with IBA. This would reduce the landfill space required by about $7 \cdot 10^{4} \mathrm{~m}^{3}$.

\section{References}

[1] Porteous, A.; Jones, G.; Frith, P.; Patel, N. Energy from Waste: A good practice guide, CIWM, 2003. 
[2] Kula, I.; Olgun, A.; Erdogan, Y.; Sevinc, V. Effects of colemanite waste, cool bottom ash, and fly ash on the properties of cement; Cement \& Concrete Research. 2001, 31 (3), 491-494.

[3] Targan, S.; Olgun, A.; Erdogan, Y.; Sevinc, V. Effects of supplementary cementing materials on the properties of cement and concrete; Cement \& Concrete Research. 2002, 32 (10), 1551-1558.

[4] Rémond, S.; Pimienta, P.; Bentz, D. P. Effects of the incorporation of municipal solid waste incineration fly ash in cement pastes and mortars I. Experimental study; Cement \& Concrete Research. 2002, 32(2), 303-311.

[5] Pera, J.; Coutaz, L.; Ambroise, J.; Chababbet, M. Use of incinerator bottom ash in concrete; Cement \& Concrete Research. 1997, 27 (1), 1-5.

[6] Filipponi, P.; Polettini, A.; Pomi, R.; Sirini, P. Physical and mechanical properties of cement-based products containing incineration bottom ash; Waste Management. 2003, 23, 145-156.

[7] Su, N.; Miao, B. A new method for the mix design of medium strength flowing concrete with low cement content; Cement \& Concrete Research. 2003, 25 (2), 215-222.

[8] Statistical office of the Republic of Slovenia, on-line data, www.stat.si

[9] Kokalj, F.; Samec, N.; Skerget. L. Combustion conditions and design control of a two stage pilot scale starved air incinerator by CFD. In: Popov, V., Itoh, H., Brebbia, C.A. \& Kungolos, S. (eds.): Waste management and the environment II, pp. 25-34. WIT Press, Southampton, Boston. 2004.

[10] EN 196-1. Methods of Testing Cement - part 1: Determination of Strength. European Standard; 1994.

[11] EN 197-1. Cement - Part 1: Composition, Specifications and Conformity for Common Cements. European Standard; 2000.

[12] Wang, K.-S.; Tsai, C.-C.; Lin, K.-L.; Chiang K.-Y. The recycling of MSW incinerator bottom ash by sintering; Waste Management \& Research. 2003, 21, 318-329.

[13] Bethanis, S.; Cheesman, C.R.; Sollars, C.J. Effect of sintering temperature on the properties and leaching of incinerator bottom ash; Waste Management \& Research. 2004, 22, 255-264.

[14] Glanvile, W. H.; Collins, A. R.; Matthews, D. D. The grading of aggregates and workability of concrete. Road Research Tech. Paper no. 5 HMSO, London, 1947.

[15] Directive 2000/76/EC of the European Parliament and of the Council of 4 December 2000 on the Incineration of Waste.

[16] Sattler, K.; Emberger, J. Behandlung fester Abfaelle, 4. ueberarb. Aufl., Vogel Verlag und Druck KG, Wuerzburg, 1995.

[17] Kuerzinger, K.; Kleine - Moellhoff, P.; Morawa, J. Moderne Verfahren zur Absorption. Firmenschrift der Fa. Noel-KRC Umwelttechnik GmbH, Wuerzburg. 1994. 